Supplement of The Cryosphere, 12, 1579-1594, 2018

https://doi.org/10.5194/tc-12-1579-2018-supplement

(c) Author(s) 2018. This work is distributed under

the Creative Commons Attribution 4.0 License.

(c) (1)

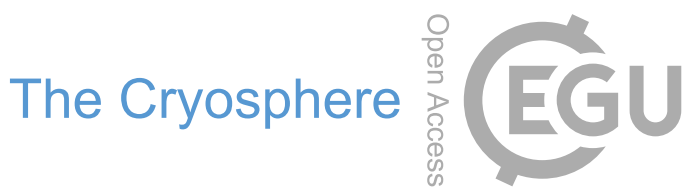

Supplement of

\title{
Using machine learning for real-time estimates of snow water equivalent in the watersheds of Afghanistan
}

Edward H. Bair et al.

Correspondence to: Edward H. Bair (nbair@eri.ucsb.edu)

The copyright of individual parts of the supplement might differ from the CC BY 4.0 License. 
Figures

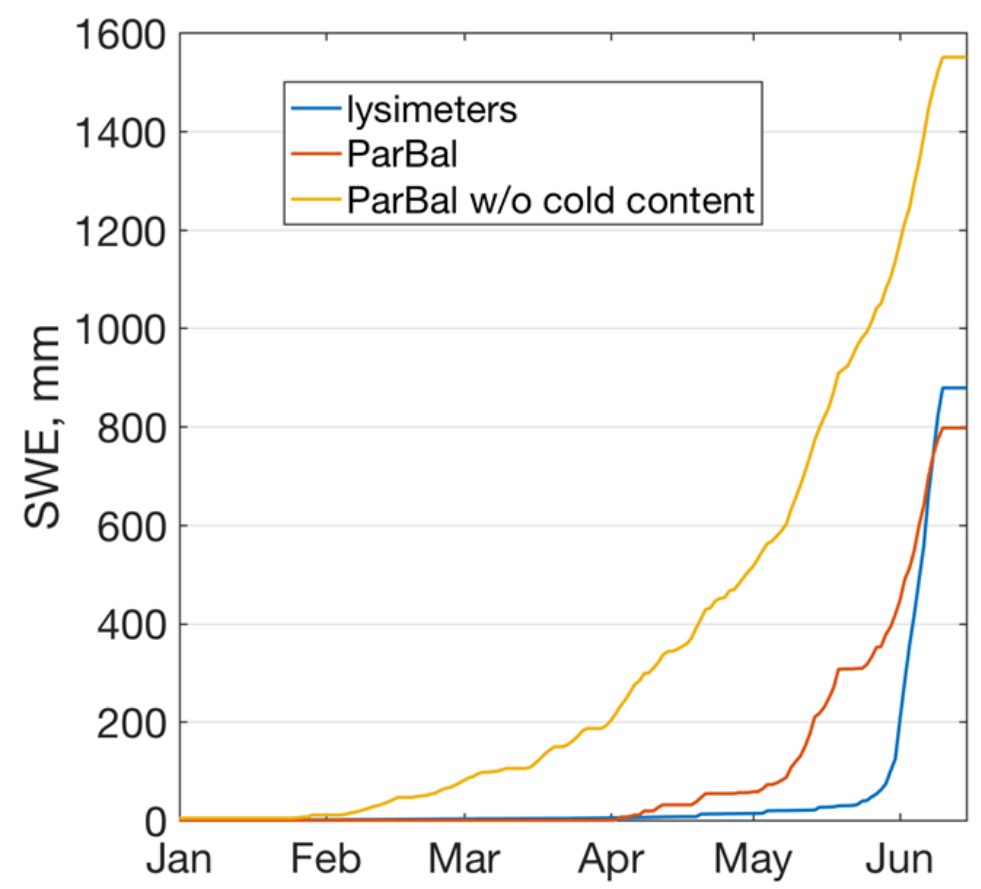

Figure S1. Energy balance SWE reconstruction using the ParBal model with and without cold content compared to the mean of 2016 lysimeter outflow at the CRREL/UCSB Energy Balance Site (Bair et al., 2015).
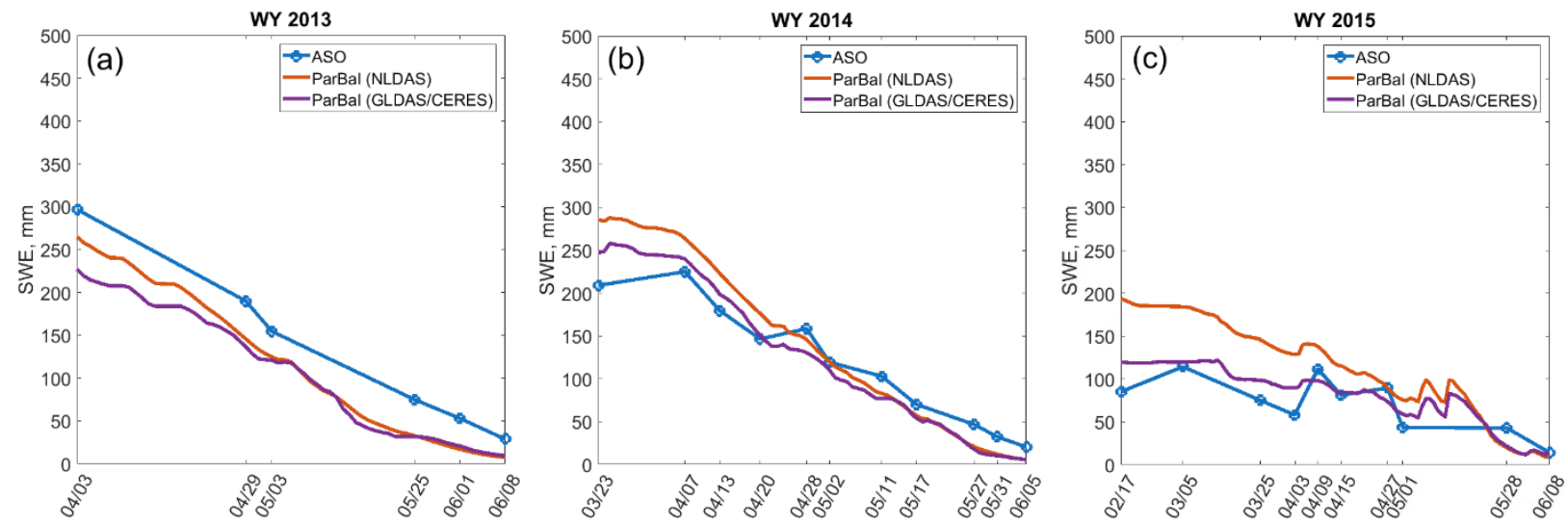

5 Figure S2. ParBal SWE reconstruction using NLDAS and GLDAS/CERES forcings compared to ASO SWE estimates in the upper Tuolumne Basin, CA USA for (a) WY 2013, (b) 2014, and (c) 2015. 

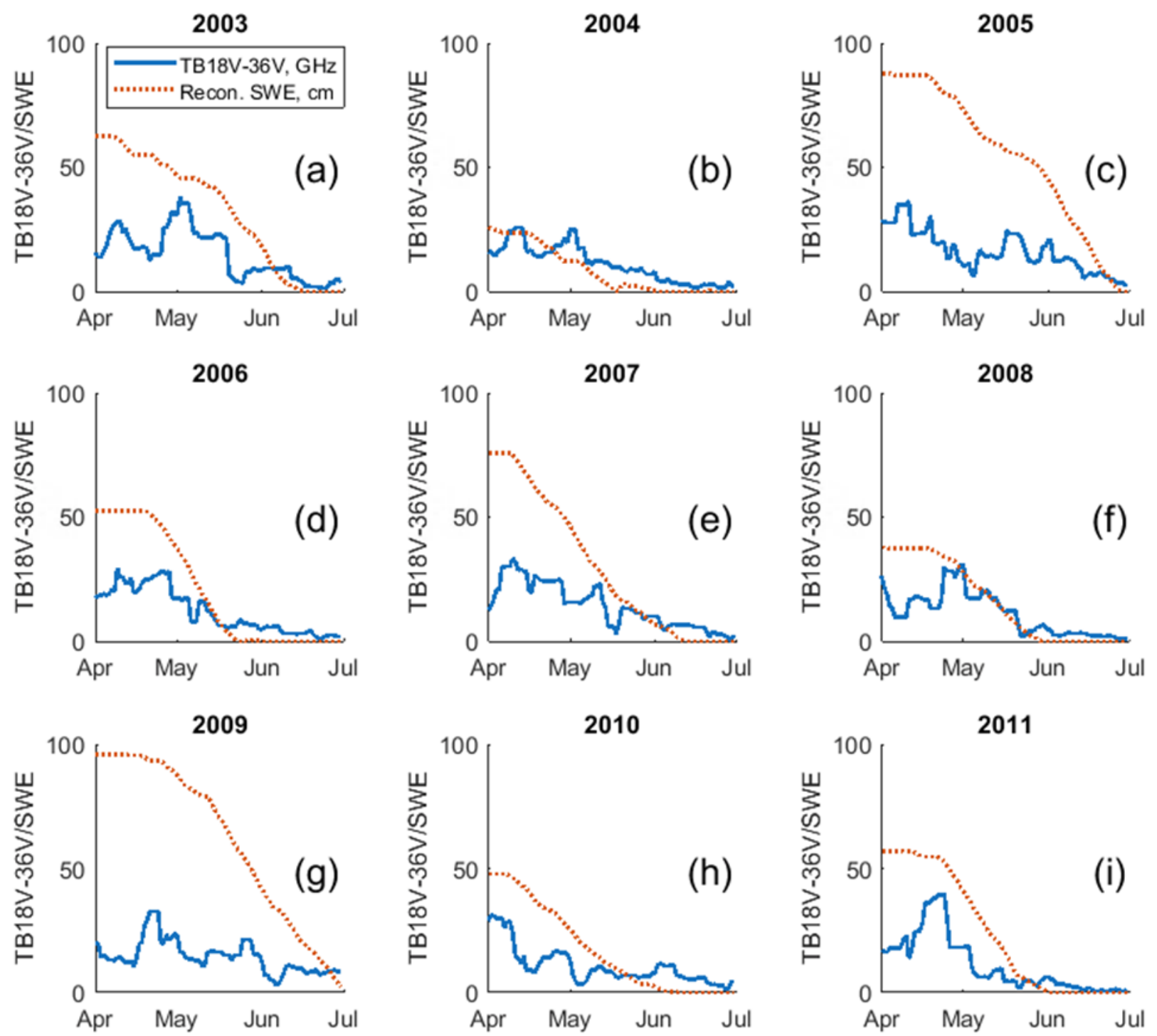

Figure S3. April through June time series of difference in passive microwave brightness temperatures and reconstructed SWE for Salang Pass Afghanistan. 
Tables

Table S1. Basin-wide SWE estimates from ParBal reconstructions using different meteorological and radiative forcings in the upper Tuolumne Basin CA compared to Airborne Snow Observatory (ASO) estimates. Bias and Mean Absolute Error (MAE) were computed from peak SWE through melt out using ASO as the truth.

\begin{tabular}{llcccc}
\hline WY & Model run & Bias, $\mathbf{m m}$ & Bias, $\%$ & MAE, $\mathbf{m m}$ & MAE, $\%$ \\
\hline \multirow{2}{*}{$\mathbf{2 0 1 3}$} & GLDAS+CERES & -42 & $-14 \%$ & 42 & $32 \%$ \\
& NLDAS & -34 & $-11 \%$ & 34 & $26 \%$ \\
\multirow{2}{*}{$\mathbf{2 0 1 4}$} & GLDAS+CERES & -11 & $-5 \%$ & 18 & $16 \%$ \\
& NLDAS & 1 & $0 \%$ & 22 & $20 \%$ \\
\multirow{2}{*}{$\mathbf{2 0 1 5}$} & GLDAS+CERES & & & & \\
& NLDAS & -5 & $-4 \%$ & 12 & $19 \%$ \\
& & 11 & $10 \%$ & 20 & $31 \%$ \\
\multirow{2}{*}{ Mean } & GLDAS+CERES & -19 & $-8 \%$ & 24 & $22 \%$ \\
& NLDAS & -7 & $0 \%$ & 25 & $26 \%$ \\
\hline
\end{tabular}


Table S2. Bias, in mm and as a percent of ASO mean, from SWE reconstructions using different forcings, binned canopy cover and elevation. GLDAS+CERES model run is from this study while the NLDAS model run is from Bair et al. (2016).

\begin{tabular}{lcccc}
\hline Canopy cover fraction & $\mathbf{0 - 0 . 2}$ & $\mathbf{0 . 2 - 0 . 4}$ & $\mathbf{0 . 4 - 0 . 6}$ & $\mathbf{0 . 6 - 0 . 8}$ \\
\hline GLDAS+CERES & $-52(-19 \%)$ & $24(17 \%)$ & $34(30 \%)$ & $38(59 \%)$ \\
NLDAS & $33(12 \%)$ & $19(14 \%)$ & $0(0 \%)$ & $2(2 \%)$ \\
& & & & $\mathbf{3 5 0 0 - 4 0 0 0}$ \\
Elevation, $\mathbf{m}$ & $\mathbf{2 0 0 0 - 2 5 0 0}$ & $\mathbf{2 5 0 0 - 3 0 0 0}$ & $\mathbf{3 0 0 0 - 3 5 0 0}$ & $\mathbf{3 5 0}$ \\
\hline GLDAS+CERES & $-7(-10 \%)$ & $10(4 \%)$ & $-59(-18 \%)$ & $-113(-39 \%)$ \\
NLDAS & $-11(15 \%)$ & $22(10 \%)$ & $57(18 \%)$ & $17(6 \%)$ \\
\hline
\end{tabular}

